\title{
LOS PROFESORES Y LA TRANSMISIÓN DE LA HISTORIA ARGENTINA RECIENTE: entre el curriculum y el contexto
}

\author{
Maria Paula Gonzalez
}

\begin{abstract}
Resumo
O objetivo deste artigo é analisar a incorporação do passado argentino recente - tanto como conteúdo de ensino quanto comemoração - por meio do estudo dos problemas e perguntas que aparecem nas escolas e entre os professores. Através de entrevistas a docentes do Ensino Médio da cidade e da província de Buenos Aires - atores educativos centrais - pudemos identificar que as tensões se articulam com a própria história do ensino de história, as tradições escolares e os diversos climas institucionais que estimulam, toleram, incentivam ou resistem a uma história próxima, complexa e traumática dos anos 70. Deste modo, podemos advertir que, com algumas dificuldades e resistências, a escola é percebida como um espaço para a transmissão e construção da memória. Palavras-chave: História recente. Argentina. Ensino de História
\end{abstract}

\begin{abstract}
The aim of this article is to analyze the incorporation of the recent past in Argentina - as much as teaching content as celebration - through the study of problems and questions that appear in schools and among teachers. Through interviews of middle school teachers from the city and state of Buenos Aires - the principal educational actors - we can identify that tensions relate to the history of the study of history, which limited, encouraged or resisted the nearby history of the complex and traumatic 1970s. In this way, we can observe that, with certain difficulties and resistances, the school is perceived as a space for the transmission and construction of memory.
\end{abstract}

Key words: Recent history. Argentina. Teaching of history

\section{Resumen}

El objetivo de este artículo es analizar la incorporación del pasado argentino reciente -en tanto contenido de enseñanza y conmemoración- indagando los problemas y preguntas que aparecen en las escuelas y entre los profesores. A través de entrevistas a docentes de nivel medio de Ciudad y Provincia de Buenos Aires - actores educativos claves-, hemos podido rastrear que las tensiones se articulan con la propia historia de la enseñanza de la historia, las tradiciones escolares y los diversos climas institucionales que estimulan, toleran, desalientan 0 resisten la historia cercana, compleja y traumática de los años '70. Asimismo, hemos podido advertir que, aun con algunas dificultades y resistencias, la escuela es percibida como un espacio para la transmisión y construcción de la memoria.

Palabras claves: Historia reciente. Argentina. Enseñanza de Historia

\section{Introducción}

La llegada de la historia argentina recientel a la escuela secundaria, que se desprende de la lectura de fuentes documentales, resulta categórica: actualmente se encuentra en los programas de historia y ciencias sociales, en la formación inicial de los profesores, en los dispositivos de actualización y capacitación docente, en las nuevas efemérides escolares 1 así como en libros de textos y variados materiales didácticos.
Aun con estas evidencias, no debemos confundir la realidad escolar con los discursos instituidos (Finocchio, 2003). En otras palabras, analizar la llegada de la historia reciente a la escuela es una cuestión que refiere no sólo a las decisiones político-educativas $(0$ a sus reformulaciones didácticas) sino también a las instituciones en su conjunto y a los profesores en particular. Por esta razón nos preguntamos: ¿Qué lecturas y traducciones realizan los profesores de los discursos oficiales? ¿Qué lugar ocupa la historia reciente en la enseñanza de la historia argentina

\footnotetext{
* Becaria Predoctoral del programa de Formación del Personal Investigador del Departamento de Didáctica de la Lengua, de la Literatura y de las Ciencias Sociales, Universidad Autónoma de Barcelona. E-mail: gonzalezamorena@gmail.com
} 
del siglo XX? ¿Cómo se materializan los actos y clases alusivas que conmemoran el pasado reciente en las escuelas?

Al plantear estos interrogantes no lo hacemos creyendo que sus respuestas surjan de la simple verificación de lo que "realmente" sucede en las escuelas, observando correspondencias 0 desviaciones con respecto a las prescripciones oficiales. Por el contrario, y como apunta Philip Jackson, en la enseñanza, como en la mayoría de los restantes actos humanos, no es tanto lo que se 've' como lo que se 'lee' (2002, p. 115); vale decir que depende de un vasto aparato de atribución de sentido que rara vez traemos a superficie $y$ examinamos. Y esta atribución de sentido no sólo refiere a las interpretaciones que se pueden señalar desde la investigación sino también a ciertos aspectos que los docentes, urgidos por las tareas de cada día, no se detienen a analizar explícitamente pero que moldean sus prácticas de forma implícita.

Por lo mismo, para una exploración de la llegada de la historia reciente a la escuela secundaria resulta imprescindible acercarnos a los profesores, a sus lecturas y traducciones del currículum, y a las múltiples variables en juego en su quehacer cotidiano.

Guiados por estas inquietudes, hemos realizado una serie de entrevistas a profesores de Ciudad y Provincia de Buenos Aires (que ejercen en secundaria, EGB3 o Polimodal) ${ }^{1}$, trabajo del que presentaremos un análisis prelimitar. ${ }^{2}$

\section{Los profesores como actores claves}

Decíamos que, para una exploración de la llegada de la historia reciente a la escuela secundaria, resulta imprescindible acercarse a los profesores. Y no lo hacemos sólo por huir de una mirada limitada a los documentos escritos o por contrastar discursos y prácticas efectivas. La intención es destacar a los docentes como actores claves y a sus lecturas e interpretaciones del currículum como actos de resignificación activa. Creemos que esto es relevante por cuanto, durante el período de reforma abierto por la sanción de la Ley Federal de Educación de 1993, maestros y profesores quedaron como ejecutores de los cambios propuestos por los "especialistas" y como colectivo que debía "capacitarse" para llevar al aula el nuevo currículum.

\footnotetext{
${ }^{1}$ A lo largo del trabajo, nos referiremos a "educación media" o "nivel secundario" a fin de unificar las alusiones a la educación secundaria de Ciudad de Buenos Aires, a la Educación General Básica 3 y a Polimodal de Provincia de Buenos Aires.

${ }^{2}$ Las entrevistas forman parte del corpus de mi tesis doctoral en curso dirigida por el Dr. Joan Pagès (UAB). Cabe advertir que nuestro propósito es ofrecer una reflexión y análisis iniciales pero no una lectura exhaustiva del tema que nos ocupa.
}

Existe una vasta investigación educativa que ha puesto de relieve cómo el currículum es moldeado y modificado por las decisiones que toma el docente. $^{3} \quad$ Estas indagaciones, sobre el pensamiento y la práctica de los profesores, han señalado que el "control" sobre qué y cómo se enseña se encuentra condicionado por un marco de referencia -referido a la concepción de sociedad, a la naturaleza del conocimiento disciplinar y a la naturaleza del pensamientoformado por una perspectiva individual, por teorías implícitas y por el conocimiento adquirido a lo largo de su vida.

Si bien estas investigaciones han tenido en cuenta el contexto de la práctica docente -como definitorio de las selecciones, ordenamientos y presentación de los contenidos-, éste ha quedado circunscrito, en ocasiones, al aula y a las características del alumnado. De la misma manera, muchas veces las decisiones de los profesores sobre el currículum se han presentado más como operaciones técnicas que como un entramado complejo atravesado por condicionantes que a veces apenas se dejan entrever (porque los propios investigadores no consideran importante iluminar 0 que, incluso, llegan a considerar como obstáculos para la innovación o porque los docentes no consideran relevante mencionar).

Por nuestra parte, creemos que es necesario ampliar la noción de "contexto" de la enseñanza de la historia y expandir el concepto de "control" del currículum teniendo en cuenta otras variables. Nos referimos al peso de la gramática escolar, a las improntas de la propia historia de la enseñanza de la historia, y a las huellas de las culturas institucionales específicas en las los profesores que se mueven.

La gramática escolar se puede definir como el conjunto de tradiciones y regularidades institucionales sedimentadas durante años; un concepto que permite explicar cómo la escuela incorpora, rechaza, modifica o distorsiona los cambios y las reformas (TYACK; CUBAN, 2001).

Las tradiciones escolares y la historia de la enseñanza de la historia también nos permiten analizar los lugares que ocupa y los formatos que adopta la historia reciente en la escuela. Reconociendo a las disciplinas escolares como productos culturales y socio-históricos (GOODSON, 1995), podemos entender por qué hoy la historia de los años '70 y la dictadura tienen un lugar en la escuela y también comprender mejor, a nuestro juicio, qué cuestiones tensionan, animan 0 desalientan a los profesores cuando la transmiten.

\footnotetext{
3 Para un panorama de estas investigaciones véanse los trabajos de Joan Pagès (2004 y 1997)
} 
Las culturas institucionales específicas también son piezas claves para explicar cómo se construyen las prácticas docentes. Permiten reconocer las exigencias, expectativas, resistencias e incluso problemas que pueden tener los profesores en determinadas instituciones en torno a la historia reciente. Además, este aspecto resulta especialmente importante cuando la "cartografía escolar" de nuestro país se revela como un agregado institucional fragmentando donde es difícil encontrar sentidos compartidos (Tiramonti, 2004).

En síntesis, entendemos que las prácticas de enseñanza se moldean por la interacción de la propia biografía de los profesores, su experiencia en el oficio docente, sus saberes, sus percepciones, su memoria, etc. Pero también creemos que existe una influencia importante de las tradiciones escolares y de los elementos contextuales (desde las propias instituciones hasta la escuela como espacio cultural y producto histórico en sentido amplio). En este trabajo, nos detendremos en rastrear estos últimos aspectos en los testimonios de los docentes.

\section{Los contenidos de historia argentina reciente}

En las entrevistas con los profesores, conversamos de variados temas: sobre su formación inicial, sus lugares de trabajo, sus alumnos, los materiales y estrategias de enseñanza, el sentido de enseñar y, claro está, sobre la transmisión de la historia argentina reciente comenzando por su lugar en las programaciones y clases. En algunos casos les preguntamos de manera amplia sobre los contenidos de las materias que incluyen la historia argentina contemporánea; en otras ocasiones nuestros interrogantes aludieron de forma general a temas de "historia reciente"; mientras que en ciertas oportunidades les consultamos directamente sobre la enseñanza de los años '70 y la última dictadura.

Las entrevistas dibujan un panorama heterogéneo acerca del lugar que ocupa la historia reciente en la enseñanza del nivel medio. En algunos casos, se presenta como un contenido programado pero prácticamente inexistente en las clases, un período al que "no se llega". En otros, aparece como un espacio temporal que se aborda mediante "grandes pantallazos", "algún comentario", "trabajos prácticos de los alumnos", etc.
Veamos cómo son expresadas estas situaciones por los propios docentes ${ }^{4}$ :

M.Paula: En otros años anteriores, ¿llegaste a dar historia argentina hasta la actualidad?

Karina: NO, no, nunca. <> Hasta peronismo... caída de Perón, el golpe del 55, pero después no. Es difícil llegar...

El año 1955, como hito temporal al que se llega en las clases de historia argentina, aparece mencionado también por otros entrevistados:

M.Paula: En 9o (EGB3) es donde vos te aproximás más a la historia argentina del siglo veinte.

Helena: sí, en 90 <>

M.P.: ¿y hasta dónde llegas?

H: siempre... hasta la caída de Perón. 1955. Es difícil porque después de Perón_primero que se requiere ya mucho tiempo para llegar a Perón.

\section{M.P.: porque estás arrancando_perdoname...}

$H$ : arranco desde... a veces, según como vengan... puedo arrancar desde 1880, ahora... si vienen mal tengo que empezar desde la caída de Rosas, en el 52.

Las palabras de esta profesora incluyen una razón para explicar por qué es "difícil llegar" a la historia reciente: las expresiones "según como vengan" y "si vienen mal" aluden a los alumnos y a sus conocimientos del continuum histórico.

Esto dejaría entrever que la selección de contenidos está más cerca de un criterio cronológico que de uno centrado en la jerarquización de temas o problemas, lo que parece enlazarse con una concepción acumulativa y enciclopedista de la enseñanza. Sin embargo, no queremos caer en evaluaciones simplistas. Es cierto que frente a la tradicional historia ordenada cronológicamente y centrada en los acontecimientos políticos se propuso una enseñanza organizada en torno a problemas sociales relevantes. Sin embargo, un relato articulado temporalmente no se contradice con la posibilidad de plantear temas y problemas

\footnotetext{
${ }^{4}$ Para la trascripción de los extractos de las entrevistas hemos usado algunas convenciones: las mayúsculas evidencian el énfasis especial en el habla. Las palabras colocadas entre los signos $=\quad=$ señalan la simultaneidad de voces entre entrevistador y entrevistado. Los signos $<>$ señalan los silencios prolongados, los puntos .... marcan las pausas más cortas, las Xxx los fragmentos inaudibles, el signo indica una autoreparación en el discurso. Las aclaraciones o explicitaciones se realizan entre paréntesis. Los recortes que hemos realizado de las entrevistas quedan evidenciados con el signo [...] Como es habitual en estos casos, los nombres de los entrevistados y de las instituciones han sido cambiados para garantizar la reserva de identidades. Como entrevistadora aparece mi nombre: $M$. Paula y luego el nombre del entrevistado. Se utilizan las letras en negrita para enfatizar algunas ideas en esta presentación.
} 
significativos (PAGÈS, 1994). Vale decir que la cuestión en ciencias sociales no se puede reducir a si se privilegian "problemas" o "continuum", sino pensar en la relevancia social, la validez científica y el potencial de transferencia de los conocimientos (GUREVICH, 1995), así como su significatividad lógica y psicológica (VEZUB, 1994). Aun así, entendemos que la preferencia por un criterio cronológico imposibilitaría alcanzar los períodos más cercanos de la historia argentina y constituya una excusa: "el pasado cercano suele ser molesto $y$, si se puede, es prudente eludirlo" (DE AMÉZOLA, 1999, p. 137).

El argumento "cronológico" vuelve a repetirse en las palabras de otra entrevistada, quien también marca la necesidad de "repasar" períodos anteriores para avanzar en el programa, lo que retrasa llegar hasta "la actualidad":

Eugenia: Este... con el programa anterior de segundo año este... había que llegar TAMBIÉN hasta la actualidad... La cosa es que no se llegaba, pero... por nada, por más que vos este... hicieras carrera veloz, pero no...

M.P.: ¿hasta dónde llegabas generalmente?

E: $y$ generalmente me quedaba... a principios de los 70. Es decir que los últimos 30 años del siglo XX no llegaba para nada. Por ahí en las últimas clases, porque los chicos tenían curiosidad... hacían preguntas, $y$ bueno, a partir de una pregunta, un pantallazo general pero no... no de otra manera. El tema era que el programa comenzaba con la organización del estado nacional, en el siglo XIX, pero obviamente para dar la organización del estado tenías que volver sobre 10 anterior. Entonces te ocupaba un tiempo repasar un poquito los contenidos de noveno [...] Y bueno, después, de allí en más empezábamos. Así que te podés imaginar: 1850, este... es mucho, es mucho por ver. [...] Y bueno, más del 60_más del 70 imposible llegar. IMPOSIB̈LE. Como mucho, 70.

Otros profesores también aluden a las características del alumnado con relación a la extensión de los programas para explicar la imposibilidad de enseñar historia reciente:

M.Paula: (retomamos la conversación luego de la interrupción) te preguntaba si vos das historia argentina del siglo $X X$, y si das particularmente el tema de los años '70 y $=$ dictadura $=$

Roberto: =bueno=, justamente, te iba diciendo. Como... está planteado el programa... este... esto se hace relativo a lo que puede ser la dinámica que cada año.

\section{Hay años que he podido darlo, otro año que no.}

M.P: ¿por... por qué?

$R$ : y... tiene que ver con la extensión de los programas, este... o por el poco tiempo xxxx demasiadas cosas, tiene que ver también con el el nivel que traen los alumnos. Este... He de confesar que en el Polimodal estamos recibiendo... chicos que son casi analfabetos funcionales. Porque la promoción en la EGB es... casi social, no es cierto?... y en el primer año se reciben alumnos que, digamos, no tienen, este... práctica así... bueno... no quiero utilizar la palabra disciplina, pero... sí práctica digamos de trabajo... de estudio, no? Les falta interpretación de textos y en primer año casi medio año para.... arreglar más o menos esas cosas. Los cursos son muy numerosos, no es cierto? Entonces eso te dificulta. Sería distinto si fueran menos [...] Así que tenemos, digamos, muchos muchas cuestiones en contra, que no siempre nos permiten llegar a... a esos momentos como uno quisiera... Lo cual no quita que... trabajando períodos anteriores se pueda hacer alguna relación hacia... el presente, pero... no... no... que... no dejan de ser relaciones... este... muy recortadas. A partir de las continuidades quizás de un período... No es fácil darlo de una forma dedicada...

A pesar que estos últimos testimonios señalan que la historia reciente no se enseña de una manera "dedicada", también muestran de qué manera aparece en las clases y de qué forma se aborda: en el caso de Eugenia por las preguntas de sus alumnos y mediante un "pantallazo general" mientras que en el caso de Roberto se efectiviza por medio de "relaciones con el presente", a partir de las "continuidades". En este mismo sentido, otra profesora comenta que ella no da "directamente" el tema aunque haya sido el contenido de algunos trabajos de los alumnos:

M.Paula: $y$ en años anteriores, ¿diste... eso de los años 60, 70, dictadura?

Beatriz: NOO, NO, nunca llegué.

M.P: tampoco

B: nunca llegué... a... ver historia... contemporánea. No, no, no. Yo, directamente, este... NO. Ehm... <> por ahí en algún bachillerato de adultos pero con trabajos prácticos, leyendo... diferentes temas en grupos $y$, bueno, cada grupo abordando un aspecto distinto. Este... por ahí de esa manera sí, pero yo particularmente no, no llego a ver. 
Este testimonio describe a los alumnos solos frente a la historia reciente -posiblemente abocados a un trabajo escrito-. Frente a esta escena podríamos discutir los alcances del aprendizaje en solitario pero preferimos apuntar a otro detalle: el desdibujamiento del rol docente en la transmisión de la historia reciente. Frente a esto, resultan sugerentes las palabras de Jacques Hassoun (1996) para quien, en la ética de la transmisión que propone, los adultos deben cumplir el rol de pasadores.

Volviendo a los estudiantes, vemos que también aparecen reflejados de otra manera: se los muestra curiosos y haciendo preguntas (en el caso de Eugenia citado anteriormente) o demandando ver el tema como lo señala el siguiente testimonio:

M.P.: y particularmente la enseñanza de historia argentina reciente, años 70 , dictadura... ¿Vos dás esos temas en la escuela?

Sandra: $A$ mí corresponden muy cole_colateralmente [...] en 30 año se da un gran, gran pantallazo de historia mundial con toques, digamos, de historia argentina. Lo que pasa es que ahí, ahí se juega también el interés de los alumnos. Muchas veces pasa, por ejemplo, con el tema de la dictadura que te piden algunos chicos y entonces yo les dedico un momento [...]

Esta entrevista señala que la historia reciente se presenta a pedido de los alumnos, mientras que otra la muestra llegando al aula "empujada" por los cambios editoriales:

M. Paula: y de historia argentina, ¿das historia argentina siglo XX?

Bárbara: sí, sí...

M.P.: y particularmente el tema de... historia argentina de los años '70, dictadura, ¿son temas que das?

B: sí, eso lo doy... Eh... yo recibo chicos con ese programa en... 5to año

M.P.: en 5to año se da ese tema...

B: sí, se da ese tema. Ahora... ahí lo que... digamos, no hubo demasiado cambio de programa. En realidad los cambios de programa más fuertes se dieron de primero a tercer año. Pero cuarto y quinto todavía son como una tierra de nadie. Este... se decidieron contenidos generales de las materias, pero no se borró ningún no hubo modificación de los programas. Lo que pasa es que con el tiempo... comenzó a aparecer bibliografía nueva, nuevos textos, y eso fue como EMPUJANDO los temas... pero en realidad no hay una discusión sobre los programas en cuarto $y$ quinto año... así que... depende mucho de la selección del material... y del profesor...

Esta última profesora alude a la situación de los programas de nivel secundario de Ciudad de Buenos Aires, jurisdicción que inició su actualización curricular en el año 2001 y que, hasta la fecha, ha publicado los programas de primer y segundo año del nivel medio. ${ }^{5}$ Lo interesante de este testimonio es que muestra que la selección de contenidos no depende solamente de los programas "oficiales" sino también de la voluntad de los profesores y de sus lecturas de los discursos historiográficos y didácticos en circulación. En efecto, una rápida mirada sobre los libros de texto escolares demuestra que la historia reciente se encuentra entre los contenidos de la oferta editorial. ${ }^{6}$

Volviendo a la selección de contenidos, no es novedad que los profesores sean los encargados de diseñar el currículum, aunque también resulta interesante señalar las diversas situaciones en que esto es realizado. Algunos docentes lo hacen en equipo, con sus colegas del área:

\section{Fernando: [...] Libertad para cada profesor e incluso para el departamento para redefinir... Nosotros los programas XXXX. Hubo acuerdo en que íbamos en quinto año a dar... nosotros damos historia argentina contemporánea. Priorizamos siglo $\boldsymbol{X X}$. Tiene que ver con xxxx. Tampoco es cuestión de llegar a antes de ayer... a veces un poco lo que algunos algunos creen que dar historia reciente... es como que tenés que ver Kirchner [...] y es una es una tontería, porque en realidad lo que se tiene que poner es lo que es significativo para la sociedad. La historia de los últimos 2, 3 10 años no me parece muy... significativos. 0 por lo menos no 10 MÁs [...]}

Otros profesores, en cambio, deciden en solitario los contenidos de historia argentina contemporánea. En este caso aparecen nuevamente los criterios cronológicos:

\section{M.Paula: ¿cómo es el programa de tu materia?}

Haydée: mirá, nunca me dieron un lineamiento fijo, entonces... este... era

\footnotetext{
${ }^{5}$ Documentos curriculares en formato electrónico disponibles en la web.

http://www.buenosaires.gov.ar/areas/educacion/curricula/media. php (fecha de consulta 6 de febrero de 2006)

${ }^{6}$ Véase por ejemplo la oferta editorial para nivel secundario y Polimodal de Aique, Santillana, Puerto de Palos y Longseller.
} 
argentina contemporánea, el único año que se veía argentina. Cuando yo me di cuenta que no tenían muchos basamentos, 10 empecé muy atrás...

M.P.: ¿dónde?

H: lo que sería... el movimiento institucional fuerte en Argentina, la constitución de las fronteras, cuando la capital se separó de las provincias, o sea Roca. Todo el grupo agroexportador y todo ese proceso... este... liberal de entonces, no? [...] Y bueno, después me di cuenta que no llegaba este.. y además las exigencias... de que había que llegar...

M.P.: ¿llegar a dónde?

H: llegar al fin del siglo XX. Yo desgraciadamente tengo ahí resquemores o un poco de prejuicio porque creo [...] que no se puede hacer historia de Alfonsín y Menem $Y A$. No sé si me explico. Lo que se hace es periodismo. Yo entiendo que Lanata empiece a escribir historia, y entiendo que Grondona u otros... pero no sé si es LA HISTORIA. No sé si me explico bien.

Lo sugerente de estos dos últimos testimonios es cómo definen la historia reciente. En el caso de Fernando, no es "cuestión de llegar a antes de ayer" o "a Kirchner" sino ver qué es lo "significativo para la sociedad". En el caso de Haydée, los períodos más recientes aluden a "Alfonsín $y$ Menem" al tiempo que plantea "dudas" acerca de si "se puede hacer historia". Estas vacilaciones posiblemente le estén planteando incertidumbres a la hora de transmitir la historia reciente a sus alumnos. ${ }^{7}$

La significatividad del pasado más cercano, por un lado, y la imposibilidad de hacer historia sobre él, por otro, han sido tópicos recurrentes en los debates a favor y en contra de la inclusión de la historia reciente en la escuela. Quienes apoyaron la inclusión del pasado reciente han sostenido que éste tiene mayor peso en la configuración de la actualidad que el que posee los tiempos más lejanos. Por el contrario, otros han desaconsejado el sesgo favorable a la focalización del tiempo histórico en la contemporaneidad (ANHRA, 2000) señalado que no debe subestimarse el condicionamiento que ha dejado en nuestras sociedades el pasado remoto. Asimismo, y hace algunos años, historiadores del mundo académico señalaban los problemas e inexistencia de historiografía de tiempos recientes ${ }^{8}, 0$, más

\footnotetext{
Se mencionan los apellidos de diversos presidentes argentinos: Alfonsin (1983-1989), Menem (1989-1995 y 19951999) y Kirchner (2003-2007)

${ }^{8}$ Véanse las palabras de Luis Alberto Romero y José Carlos Chiaramonte vertidas en el Diario Clarín en 1997 citadas por Gonzalo de Amézola (1999).
}

cercanamente, el carácter necesariamente ensayístico de sus aproximaciones. Afortunadamente, flamantes publicaciones demuestran que la historia reciente es un ámbito temporal que comienza a investigarse sistemáticamente no sólo por politólogos y sociólogos sino también por historiadores que han roto "con el viejo presupuesto positivista predominante desde el siglo XIX que se negaba a analizar la historia reciente por falta de 'perspectiva temporal'"'(SURIANO, 2005, p. 11)

Pero más allá de los debates, parece cierto que escuela y pasado reciente no han sido términos hermanados. Por el contrario, los programas escolares han tenido desde siempre una "alergia a la actualidad" (TENTI FANFANI, citado por J ABBAZ; LOZANO, 2001, p. 119), asociada ésta con el reino de las pasiones e intereses inmediatos, inadmisibles para una escuela entendida como espacio para inculcar conocimientos y valores cuya verdad y vigencia están fuera de discusión.

La escuela como espacio neutral sigue siendo una ilusión pertinaz que la historia reciente pone en cuestión innegablemente. Esta tensión aparece, quizás de modo más evidente, alrededor de los actos conmemorativos, cuando el tratamiento de la historia reciente no sólo ocupa la programación de historia argentina sino a la escuela en general.

En el siguiente apartado presentaremos el panorama del lugar y los formatos escolares de las nuevas efemérides de la memoria según los testimonios de los profesores.

\section{Las efemérides del pasado reciente}

La situación de la conmemoración de las nuevas efemérides relativas a la historia reciente es tan heterogénea como la enseñanza de contenidos descrita en el apartado anterior. En ocasiones resulta de una variedad extrema. En algunos casos, las efemérides se omiten en los calendarios diseñados por la escuela y no se realizan. En otros, se les da el espacio de una jornada especial con suspensión de clases y organización de actividades relativas a la fecha. Entre estos dos polos encontramos escenarios intermedios: la conmemoración queda a voluntad de los profesores; los directivos convocan y comprometen a los profesores a realizar las clases en la primera hora de la fecha señalada en el calendario; los actos se realizan ocasionalmente a escala institucional cuando los alumnos forman en el patio al comenzar la jornada escolar; los actos son organizados por los propios alumnos, etc.

Veamos cómo los profesores describen algunas de estas situaciones: 
M. Paula: Viste que se agregaron conmemoraciones como el 24 de marzo, el 16 de setiembre...

Eugenia: (hace una mueca y susurra) Acá nada (se refiere al colegio católico donde estamos realizando la entrevista) $<>$ En el Estado, sí. El 16 de setiembre se trabaja mucho [...]

Esta profesora, que ejerce en escuelas públicas y privadas, advierte la diferencia entre los dos espacios donde trabaja, situación que queda demostrada con el calendario del colegio confesional donde sólo se incluyen las efemérides "clásicas": 25 de mayo, 20 de junio, 9 de julio, etc. Esta escuela queda anclada, así, en una historia patriótica que enaltece la memoria de los héroes de la nación argentina, como dispusiera el Estado decimonónico en la génesis del sistema educativo. Parece claro que las efemérides clásicas colocan a la escuela ante un tiempo glorioso mientras que las nuevas conmemoraciones la sitúan frente a un pasado "vergonzante" (JELIN; LORENZ, 2004, p. 5), a la incomodidad, el dolor, la perplejidad y la vergüenza (RAGGIO, 2002), que en algunos casos se procura soslayar.

La diferencia en los climas institucionales respecto a las efemérides de la memoria también es mencionada por otros entrevistados que manifiestan distintos posicionamientos según los ámbitos de trabajo. Es el caso de Natalia, una profesora que trabaja en una escuela estatal y en una escuela privada bilingüe, que lo expresa de la siguiente manera:

Natalia: y en la privada... se trabaja pero mucho más... viste... (hace un gesto de superficialidad) Lo que pasó, a ver qué recuerdan, si saben algo, se trabaja así con un torbellino de ideas pero queda todo... no,

no, no demasiado compromiso, viste? Porque tampoco les interesa... eso es 10 que yo noto, entendés? Yo también tengo una postura mucho más moderada en este lugar, pero... ellos mismos no, no es algo que los motive. En cambio en el colegio del estado dan, aportan, porque se nota que son temas charlados en la casa.

En otros casos, el clima institucional es propenso a trabajar las nuevas efemérides. Es lo que describe un profesor que trabaja en una escuela pública, a la que describe como un espacio en el que existe una "tradición" de conmemorar el pasado reciente:

M. Paula: [...] viste que los calendarios de Ciudad habían puesto este tema de dar la clase del 24 de marzo..., hacer un acto el 16 de setiembre... ¿esto en la escuela se hace? $=10$ hacen $=$

Fernando: =sí=, sí. Se hace...

M. Paula: ¿las dos cosas?

F: Sí, sí se hacen dos y más también, porque como es un colegio con centro de estudiantes, aunque en decadencia, digamos, y en proceso de descomposición, como tuvo un centro de estudiantes muy fuerte hasta hace cuatro años digamos, quedó esa tradición. $Y$ siempre algún pibe, algún grupito toma la posta, y entre las cosas que los pibes hacen está organizar actividades para el 24 de marzo, generalmente está definida como de jornada, una especie de jornada especial, donde no hay clases sino que hay reuniones tipo asamblea, donde hay un expositor, se invita a alguien, los pibes hacen alguna actividad especial, se ve una película..

En los testimonios que expresan que la conmemoración queda a voluntad y criterio de los profesores, encontramos también diversas lecturas e interpretaciones de lo que significa conmemorar, por ejemplo, el 24 de marzo.

Lorena: [...] He llegado a tomar un mes. En realidad eso lo hice una vez que pasé la película "La República Perdida dos", que plantee todo un análisis EXHAUSTIVO de eso. Pero producto de $<>$ algunas reacciones que tuve de alumnos y de los padres a empezar el año trabajando ese tema, y bueno más en la escuela donde trabajo donde hay una población de hijos y nietos de integrantes de las fuerzas ammadas, me parecía que era mejor trabajar estos temas en profundidad, digo pensando que hay que trabajarlos en profundidad pero no el formato efeméride sino en el contexto de un profesor y de una enseñanza más amplia.

Este testimonio contrasta con otras opciones, como la de una profesora de la misma escuela:

Haydée: [...] Yo siempre hago eh <> un breve comentario los primeros 10-15 minutos.

En lo señalado hasta aquí, se hace evidente la influencia del contexto escolar en la conmemoración de las nuevas efemérides. Esta consideración, sin embargo, no implica que establezcamos una continuidad entre tipos de escuelas y prácticas docentes, puesto que un profesor actúa de distinta manera según las escuelas (el caso de Natalia) pero también hay 
otros docentes que plantean la transmisión de la historia reciente de una manera muy disímil aún trabajando en la misma institución (como los ejemplos de Lorena y Haydée) Si el contexto influye en la tarea docente también lo está haciendo su biografía, su concepción de historia, su memoria y conciencia histórica, entre otras cuestiones. $^{9}$

Volveremos ahora a los formatos escolares. Muchas veces, aunque las disposiciones oficiales señalen que los actos evocativos del pasado reciente deben ser realizados con la participación de toda la comunidad escolar, las conmemoraciones quedan circunscritas al ámbito áulico. Esta situación de "puertas cerradas" es descrita por un profesor de la siguiente manera:

Roberto: a ver... si es por los actos, la modalidad que existe es llamar varios profesores, generalmente por área... hay actos que los hacen el área de ciencias sociales, el área de ciencias naturales, y medio se reparte el trabajo. $Y$ en general... acá por lo menos, la tradición ha querido que cada vez que estoy involucrado yo, es como que me dejan a mí el tema del discurso.... no sé por qué (risas)

M.Paula: (risas) [...] Y con el 16 de septiembre ¿hiciste algún discurso?

R: No. No. No porque... eso... El caso de las fechas que vos mencionabas, el 24 de marzo, el 16 de setiembre, eh... por 10 menos acá en la provincia de Buenos Aires, me da la sensación que lo tienen más de... de forma... que tiene que estar que porque haya un, un sentir... es decir, como un proyecto de país que eso deba estar, así que en general, lo más lavado posible... Rara vez ha habido una formación para eso... Es en las aulas, en el pizarrón...

En otros casos, las clases alusivas, aunque realizadas en el aula, se organizan institucionalmente y los profesores son convocados en su conjunto. Así lo relata una directora de una escuela media de Provincia de Buenos Aires.

M.Paula: ¿cómo se maneja aquí en la escuela, vos como directora, el tema del calendario escolar que marca estas nuevas conmemoraciones... como el 24 de marzo?

Fernanda: Eh... en realidad nosotros, por ejemplo se maneja... institucionalmente. Nosotros el 24 de marzo lo que hicimos fue... repartirle a los chicos la carta de Rodolfo Walsh a la Junta y se trabajo en

\footnotetext{
${ }^{9}$. El análisis de estos factores excede el espacio de este trabajo por lo que hemos ponderado, en esta oportunidad, analizar los condicionantes contextuales.
}

cada aula y... se hicieron afiches sobre... qué significaba... el concepto de dictadura y democracia, en realidad el quiebre del 24 de marzo más allá de todo tiene que ver con un quiebre institucional, y bueno... hay que defender la democracia a partir del, del reconocimiento de lo ocurrido... así que hemos trabajado con eso.

M.P.: ¿y esto_a quiénes convocaste para hacer este trabajo?

F.: en realidad a todos los profesores que tenían la primera hora el 24 de marzo. A TODOS...

M.P.: desde... el de... no sé... de matemáticas... hasta...

F.: Sí, porque todos son ciudadanos argentinos. Más tarde o más temprano todos sabemos lo que pasó es día. El que no, sería bueno que 10 recuerde. Ninguno nació después de esa fecha. Y si nació después del 76 vive en este país donde ha existido el Juicio a las Juntas o sea... es bueno que también sean ciudadanos. Con el tema de algunos actos, también es así. No es que SOLAMENTE algunos profesores. Todos son iguales. $Y$ los actos se reparten por departamentos. No es esto de que SÓLO los de sociales tienen que saber. El resto es exactamente igual...

Continuando la conversación, esta vez sobre las conmemoraciones adoptan la modalidad de "acto", esta directora señala el patio y la formación como espacio de reunión y memoria:

\section{M.P.: ¿y con el 16 de setiembre?}

Fernanda: en líneas generales, se organiza desde... 10 hacemos desde distintos... ámbitos. Por ejemplo, el 16 de setiembre en líneas generales hago un discurso explicando que... contando qué había sucedido porque tengo la misma edad que los chicos que de la Noche de los Lápices. 0 sea que <> Esto de contarles a los chicos qué significa estar en una escuela y de golpe no entender que pasaba alrededor de uno. Y... por otro lado, después los alumnos, que en líneas generales 10 hacemos con los chicos de, de humanidades y ciencias sociales, hacen un, un discurso. $\boldsymbol{Y}$ se hace, bueno, con formación... con todo [...]

Las marcas de la memoria personal, que aparecen en las palabras de esta directora, son sin duda interesantes, aunque dejaremos su análisis para otra oportunidad. Nos interesa destacar las señales que apuntan a las tradiciones escolares generales, puesto que también aparecen en otros testimonios. Es el caso de una profesora que, en la 
entrevista, advertía los riesgos de ritualización de los actos conmemorativos del pasado reciente:

Bárbara: [...] Más que un discurso, no es [...] si no se les da un espacio diferente, quedan en eso: una fecha más.

M. Paula: ¿Eso es lo que vos crees que está pasando?

\section{B: Si, incluso cuando fue el tema de la Amia, que por unos años se hacía una conmemoración, al hacerlo tan formal, pierde fuerza.}

La observación de esta profesora entra en consonancia con lo advertido por algunos autores, que ven a la escuela respondiendo con elementos clásicos de su repertorio (GUELERMAN, 2001, p. 38) (el patio, la formación, el discurso) ante la interpelación de transmitir y conmemorar la historia reciente.

Volviendo a los contextos particulares, los de cada escuela, decíamos que éstos son los ámbitos que hacen a la conformación de las prácticas docentes y los espacios donde se desarrollan. Así, encontramos un variado arco de actitudes frente a los docentes que pretenden acercarse a la historia reciente: expectativas, resistencias, exigencias, renuencias, omisiones 0 incluso problemas explícitos.

Con relación a este aspecto, citamos nuevamente el caso de Lorena. En él vemos que el colegio confesional en el que se desempeña como profesora -y donde, según sus palabras, asisten hijos y nietos de integrantes de las fuerzas armadas- no ha interferido aunque tampoco fomentado el trabajo sobre el 24 de marzo:

M.Paula: ¿tuviste algún problema con las autoridades de la escuela... cuando tuviste que plantear estos temas, enseñar la historia argentina reciente?

Lorena: No, no tuve problemas con las autoridades en particular, pero digo tampoco hubo una voluntad real de instalar el tema y dar este tema, de trabajar desde el área o desde otras áreas. [...]

De todas maneras, antes de registrar la entrevista, Lorena nos había comentado que en una oportunidad había recibido quejas explícitas de un padre que la acusaba de mirar la historia "con un solo ojo" -en una carta dirigida a las autoridades-, situación ante la cual los directivos le aconsejaron tratar de dar las "dos versiones" sobre el 24 de marzo.

En otros casos, los problemas en torno a la historia reciente se hacen más explícitos. Volvemos, aquí también, a un caso ya citado, el de
Natalia, quien había manifestado tener un posicionamiento distinto en la escuela privada bilingüe fundado en una situación con las autoridades de la escuela:

Natalia: [...] Y a mí me pasó, con el director, para los diez años de la democracia_no... porque en esa época no trabajaba... Entré en el 95 <> Bueno, no sé qué año yo había hecho un trabajo espectacular con los chicos con recortes, habíamos empapelado todo_las escaleras, o sea todas las partes públicas, digamos. Me hicieron sacar... TODO <> Y yo digo, yo no viste... es muy doloroso trabajar con los chicos en un montón de cosas y que después te 10 saquen... Realmente... no_no tengo ganas de sufrir de esa manera, prefiero trabajar... O sea, tengo cosas muy buenas, pero en esto yo sé que no puedo profundizar porque es ir al choque y la verdad es que no... Yo tengo que trabajar sí o sí, no puedo darme el lujo de que me echen... y no tengo ganas de generarme un conflicto.

Parece claro, a partir de este testimonio, que ciertas culturas institucionales desalientan la transmisión de la historia reciente ya que es un tema que genera "conflicto" con los directivos.

Pero el tema no sólo resulta conflictivo para con las autoridades sino también entre los propios profesores. En la entrevista con Roberto, al buscar él mismo explicaciones acerca de las resistencias de sus colegas por tratar la historia reciente y realizar las conmemoraciones, comenta lo siguiente:

Roberto: [...] Porque hay que tener en cuenta una cosa, esto es más una opinión personal, uno supone que después de tanto tiempo, el discurso de cualquier colega en función del 24 de marzo o del 16 de setiembre debe ser crítico hacia lo que fue la dictadura militar... nos olvidamos a veces cuál pudo haber sido la posición que estos docentes tuvieron durante esos eventos... y por ahí, si fue favorable o incluso a veces militantemente favorable hacia la dictadura, ponerlo en el compromiso de que tiene que hacer un discurso que sabe que tiene que ser en contra, es... negativo, es chocante... Yo acá dentro de esta escuela incluso te podría señalar uno o dos, no es cierto?, que... este... han sido militantes del lado de la dictadura... no lo saco ni lo ventilo, porque bueno... porque tampoco es cuestión de venir a hacer este... de armar conflicto porque no es el lugar adecuado. Pero, son fechas que... este... que chocan todavía, que producen eh... roces y chispas. Por eso a veces... acá hay mucho, hay mucha... este... 
complejo de culpa con estas cosas, todavía. Es decir, no es un, no es un... es esta parte de nuestra historia que no está digerida socialmente todavía... enfrentamientos, bueno, vos lo verás a través de los medios de comunicación, con los actos que hay, sobre todo en esos días, cuando empiezan a aparecer cartas de lectores, en uno y otro sentido, y se ve que la cosa está dividida todavía...

Quizás como ningún otro contenido que transmita la escuela, el pasado reciente pone de manifiesto que los docentes no son tabla rasa y que "portan supuestos, preferencias, experiencias vivenciales de ese pasado, pertenencias a grupos sociales e idearios de sociedad" (RAGGIO, 2002: 45). Asimismo, las conmemoraciones, los actos, las clases alusivas demuestran que "la memoria es una política. La memoria es un territorio de conflictos. La memoria nunca es ingenua, nunca es neutral, nunca es objetiva. La memoria no es un retorno a lo ya acontecido. No es un dispositivo objetivo. No es una mera acumulación de información" (FORSTER, 2002, p. 16). La memoria es reconstrucción, resignificación del pasado desde el presente y desde las expectativas de futuro. Es también, necesariamente, olvido, recorte y selección.

Lo que se advierte en la escuela, y en la sociedad en general, es que no hay una memoria social sino varias "memorias en conflicto", es decir, la lucha de múltiples actores sociales y políticos que van estructurando relatos sobre el pasado con la intención de "establecer/ convencer/ transmitir una narrativa, que pueda llegar a ser aceptada" (JELIN, 2002, p. 39)

\section{Reflexiones finales}

Lo dicho hasta aquí nos lleva a formular una serie de reflexiones finales que presentamos a continuación.

1. La escuela como lugar para la transmisión de la historia reciente.

En ningún testimonio se expresa abiertamente el rechazo por enseñar la historia reciente. Las controversias que pudieran existir se encuentran encubiertas por la selección de contenidos: sencillamente se evita el tema. En otros casos se manifiestan dudas acerca de la posibilidad de historizar el pasado reciente, lo que plantearía incertidumbres acerca de la viabilidad 0 conveniencia de su transmisión escolar.

Tampoco se impugna a la escuela como espacio para la construcción y la transmisión de la memoria. En ocasiones se discuten los formatos 0 las limitaciones de los actos o las clases alusivas (advirtiendo los riesgos de la ritualización o prefiriendo el tratamiento de estos temas en el contexto más amplio de las materias), pero no la importancia de la conmemoración.

Lo que parece evidente es que, si la escuela tradicionalmente acogió entre sus funciones la formación de una conciencia nacional a través de la glorificación del pasado nacional, la conmemoración del pasado reciente, donde ya no hay héroes sino víctimas, le provoca más incomodidad y problemas. La escuela no parece habituada a las controversias y la enseñanza de la historia tampoco está acostumbrada a que el sentido sobre lo que pasó no esté fijado de manera definitiva. ${ }^{10}$

2. El peso de las tradiciones escolares y las huellas de las culturas institucionales.

Los relatos docentes dejan entrever notables diferencias en torno a las conmemoraciones de la historia reciente. En el caso de los actos alusivos, algunas escuelas omiten las fechas en los calendarios, en otras se realizan en el ámbito "privado" del aula, en algunos colegios se cumplen en el patio de la escuela, mientras que en otros forman parte de su tradición, etc.

Estos contrastes se explican fundamentalmente por las culturas institucionales que modelan la práctica docente y que estimulan, toleran, desalientan, resisten 0 incluso rechazan la conmemoración de la historia reciente. Pero también es evidente que los docentes responden de diversa manera ante esos climas, especialmente en aquellas escuelas que dejan la transmisión del pasado reciente a la voluntad de los profesores. Allí, entonces, entrarían en juego variables como su biografía, sus experiencias vitales, su memoria del pasado reciente, sus compromisos políticos y sociales, su concepción de la historia y su conciencia histórica, etc.

3. Los profesores como actores claves en la transmisión de la historia reciente.

Los profesores leen, interpretan y traducen las prescripciones oficiales en torno a la enseñanza de la historia reciente de manera diversa. En algunos casos, el pasado reciente es un período que, aunque se incluye en los programas, no se llega a enseñar por la extensión de los mismos. En otros, es un tema que directamente se omite y ni siquiera se menciona. En ciertos casos es un contenido en torno al que los profesores se sienten

\footnotetext{
${ }^{10}$ Paul Ricoeur (1999) señala la diferencia entre acontecimiento real y hecho histórico apuntando que "lo pasado" es algo imborrable y que no puede deshacerse, pero "el sentido" de lo que pasó, por el contrario, no está fijado de una vez por todas.
} 
especialmente comprometidos, por su propia voluntad o por demanda expresa de sus alumnos. En otros, las aproximaciones a la historia reciente se traducen en rápidos vistazos al final del año, algunas alusiones a propósito de otros temas, 0 trabajos prácticos de los alumnos.

El ordenamiento cronológico del currículum de historia parece seguir siendo el criterio principal para la selección de contenidos entre los docentes que expresan "no llegar a la historia reciente". La persistencia de este criterio cronológico podría estar ligada a evitar el pasado más cercano aunque ningún testimonio lo declare abiertamente.

Lo resulta evidente es que la construcción de las prácticas docentes se realiza entre las tensiones y posibilidades del currículum y del contexto, en las que confluyen diversos condicionantes. Así, se avizoran intersticios que son "ocupados" de manera diversa por los profesores.

A lo largo de este trabajo hemos tratado de dar cuenta de la complejidad del fenómeno educativo que constituye la práctica docente. Creemos que resulta necesario seguir buceando sobre aspectos del oficio de enseñar que han sido poco documentados pero que resultan claves en la transmisión escolar de la historia reciente; máxime cuando ya han pasado treinta años del último golpe militar en la Argentina y esta historia sigue abierta y presente.

\section{Referencias}

1. ANHRA. Academia Nacional de la Historia de la República Argentina. Informe de la Comisión de enseñanza de la historia. Buenos Aires: mimeo., 2000.

2. DE AMÉZOLA, G. Problemas y dilemas de la enseñanza de la historia reciente. En Entrepasados, Revista de Historia, n. 17, p. 137-162, 1999.

3. FINOCCHIO, S. Apariencia escolar. En Dussel, I.; Finocchio, S. (comp.) Enseñar Hoy: Una introducción a la educación en tiempos de crisis. Buenos Aires: Fondo de Cultura Econômica, 2003.

4. FORSTER, R. La memoria como campo de batalla. Revista Puentes, v. 2, n. 8, p. 14-17, 2002.

5. GOODSON, I. Historia del currículum. La construcción social de las disciplinas escolares. Barcelona: Pomares-Corredor, 1995.

6. GUELERMAN, S. Escuela, juventud y genocidio. Una interpelación posible. En Guelerman, S. (comp.) Memorias en presente. Identidad y transmisión en la Argentina posgenocidio. Buenos Aires: Editorial Norma, 2001.

7. GUREVICH, R. Un desafío para la geografía: explicar el mundo real. En Aisenberg, B. y Alderoqui, S. (comps.) Didáctica de las ciencias sociales: aportes y reflexiones. Buenos Aires: Paidós, 1995.

8. HASSOUN, J. Los contrabandistas de la memoria. Buenos Aires: Ediciones de la Flor, 1996.

9. JABBAZ, M.; LOZANO, C. Memorias de la dictadura y transmisión generacional: representaciones y controversias. En: GUELERMAN, S. (comp.). Memorias en presente. I dentidad y transmisión en la Argentina posgenocidio. Buenos Aires: Norma, 2001.

10. JACKSON, P. Práctica de la enseñanza. Buenos Aires: Amorrortu, 2002.

11. JELIN, E. Los trabajos de la memoria. Buenos Aires: Siglo Veintiuno, 2002.

12. JELIN, E.; LORENZ, F. Educación y memoria: entre el pasado, el deber y la posibilidad. En: JELIN, E.; LORENZ, F. (comps.) Educación y memoria. La escuela elabora el pasado. Buenos Aires: Siglo Veintiuno, 2004.

13. PAGÈS, J. Enseñar a enseñar historia: la formación didáctica de los futuros profesores de historia. En E. NICOLÁS, E.; GÓMEZ. J. (coords.) Miradas a la Historia Universidad de Murcia: Servicio de Publicaciones, 2004. p. 155 - 178.

14. PAGÈS, J. Líneas de investigación en didáctica de las ciencias sociales. En: BENEJAM, P.; PAGÈS, J. (coords.) Enseñar y aprender ciencias sociales, geografía e historia en la educación secundaria. Barcelona: ICE UB \& Horsori, 1997.

15. PAGÈS, J. La Didáctica de las Ciencias Sociales, el currículum y la formación del profesorado. Signos. Teoría y práctica de la educación, 13, p. 38-51, 1994.

16. RAGGIO, S. Cuando la escuela da la palabra. El rol de la educación formal en la transmisión del pasado. Revista Puentes, n. 7, p. 41-46, 2002.

17. RICOEUR, P. La lectura del tiempo pasado: memoria y olvido. Madrid: Arrecife-UAM, 1999.

18. SURIANO, J. Introducción: una Argentina diferente. En: SURIANO, J. (dir.) Nueva Historia Argentina, tomo $X$ "Dictadura y democracia (1976-2001)". Buenos Aires: Editorial Sudamericana, 2005.

19. TIRAMONTI, G. (comp.) La trama de la desigualdad educativa. Mutaciones recientes en la escuela media. Buenos Aires: Manantial, 2004. 
20. TYACK, DAVID; CUBAN, L. En busca de la utopía. Un siglo de reformas de las escuelas públicas. Buenos Aires: Fondo de Cultura Econômica, 2001.

21. VEZUB, L. La selección de contenidos curriculares: los criterios de significatividad y relevancia en el conocimiento escolar. Entrepasados, Revista de Historia, n. 7, p. 151166, 1994.

Recebido em 22/11/2007

Reformulado em 10/05/2008

Aceito em 30/05/2008 